\title{
Una nueva especie de Connarus (Connaraceae) Para Costa Rica
}

J. Francisco Morales

\begin{abstract}
RESUMEN
(Una nueva especie de Connarus (Connaraceae) para Costa Rica) Se describe Connarus vulcanicus J. F. Morales, un nuevo taxón endémico a la Cordillera de Guanacaste en Costa Rica. Se incluyen una descripción completa, ilustraciones y comentarios de la relación con C. schultesii Standl., la especie morfológicamente más relacionada. Se brinda una clave para las especies del género en Costa Rica.
\end{abstract}

Palabras clave: Connaraceae, Connarus, Costa Rica, América Central.

\begin{abstract}
(A new species of Connarus (Connaraceae) from Costa Rica) Connarus vulcanicus J. F. Morales, a new species endemic to the Cordillera of Guanacaste in Costa Rica is described and illustrated and its relationship with G. schultesii Standl. is discussed. A key to the species of the genus Connarus in Costa Rica is included.
\end{abstract}

Key words: Connaraceae, Connarus, Costa Rica, Central America.

El género Connarus es el más grande de la familia Connaraceae, con cerca de 100 especies ampliamente distribuidas en el paleotrópico, pero con una mayor cantidad de taxones en el neotrópico (Forero, 1983; Forero \& González, 2001), donde ca. de 55 especies son conocidas. Este género se puede confundir con Rourea, pero se puede separar por sus flores con pétalos usualmente con puntos glandulares (vs. puntos glandulares ausentes), ovario unicarpelar (vs. ovario con cinco carpelos) y frutos usualmente estipitados (vs. no estipitados). Durante el proceso de elaboración de las Connaraceae para el Manual de Plantas de Costa Rica, se encontró la siguiente novedad, con cuyo descubrimiento sube a cinco el número de especies del género conocidas en el país.

Connarus vulcanicus J. F. Morales, sp. nov. Tipo: COSTA RICA. ALAJUELA: Guatuso, Parque Nacional Volcán Tenorio, cuenca del Río Frío, Alto Masís, 8.IV.2000, fl., J. Chaves \& Muñoz 373 (Holotipo INB). Fig. 1

A Connarus schultesii Standl. affine, foliolis minoribus $(4,2-9,5 \times 2-4,1 \mathrm{~cm}$ vs. (7-)8,2-19(-20,1) × 2,5-7,9 cm), petalis extus ferrugineo-puberulis (vs. glabris), 2,5-2,8 mm longis (vs. 4,1-4,4 $\mathrm{mm}$ ) et folliculis extus glabris vel glabratis differt.

Lianas leñosas, los tallos diminuta y densamente puberulentos cuando jóvenes, glabrescentes o glabros con la edad, esparcidamente lenticelados. Hojas generalmente trifolioladas, raramente alguna bifoliolada, los folíolos 4,2-9,5 × 2-4,1 cm, elípticos, la base obtusa a redondeada, el ápice agudo o cortamente acuminado, la lámina sin puntuaciones, glabra, peciolo 2,7$7,1 \mathrm{~cm}$, peciolulos $2-5 \mathrm{~mm}$. Inflorescencias paniculado-espiciformes, densamente ferrugíneo-tomentulosas cuando jóvenes, el indumento más esparcido con la edad, algunas veces glabrescentes en fructificación, las flores pediceladas, con los pedicelos 12,3 $\mathrm{mm}$, brácteas ca. $1 \mathrm{~mm}$, escariosas; sépalos 2-2,5 mm, elípticos a ovado-elípticos, el ápice agudo a obtuso, densamente ferrugíneo-tomentulosos externamente; pétalos 2,5-2,8 $\mathrm{mm}$, esparcidamente ferrugíneo-puberulentos externamente, ovario

Artigo recebido em .05/2005. Aceito para publicação em 05/2006.

Instituto Nacional de Biodiversidad (INBio), Apartado 22-3100, Santo Domingo, Heredia, Costa Rica. fmorales@inbio.ac.cr 
densa a moderadamente ferrugíneopuberulento. Frutos 3-3,8 $\times 1,6-2 \mathrm{~cm}$, rojos al madurar, estipitados, inconspicuamente ferrugíneo-puberulentos externamente cuando jóvenes, glabros o glabrescentes con la edad, usualmente sin puntuaciones negras, muy esparcidamente puberulentos internamente.
Distribución, habitat y ecología. Endémica por el momento a Costa Rica donde está restringida a la Cordillera de Guanacaste; crece en bosques nubosos y ventosos, en elevaciones de 550 a 1200 m. Especímenes con flores han sido recolectados en abril. Material con frutos ha sido recolectado en febrero, abril, mayo, junio y noviembre.

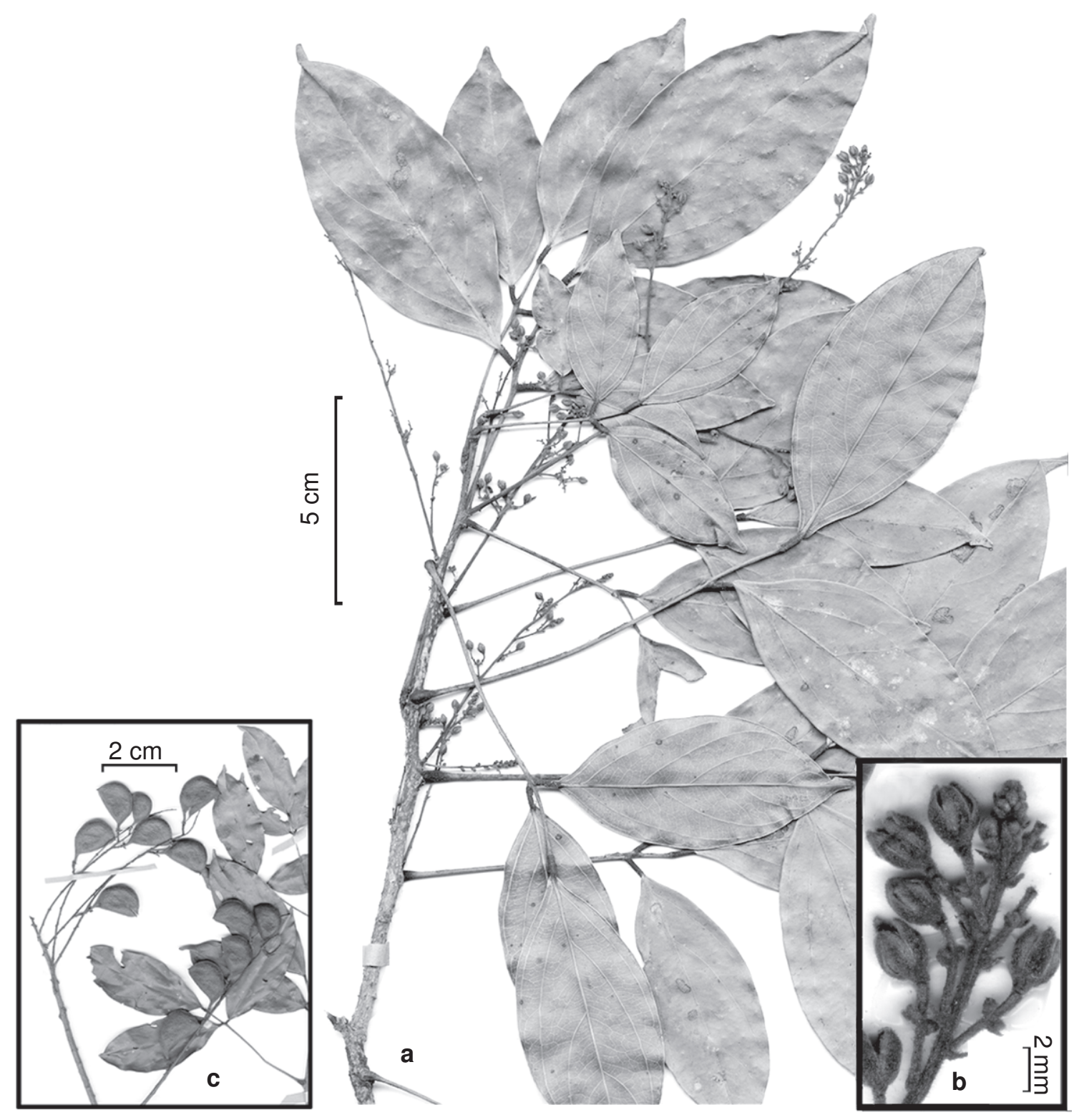

Figura 1 - Connarus vulcanicus J. F. Morales (a-b Chaves \& Muñoz. 373; C Espinoza 841, INB). a. Ramita con inflorescencias. b. Detalle de las flores. c. Detalle de los frutos. 
Connarus vulcanicus es similar a $C$. schultesii Standl., endémica a México, pero se puede separar con facilidad por sus pétalos más cortos $(2,5-2,8$ vs. $4,1-4,4 \mathrm{~mm})$, esparcidamente ferrugíneo-puberulentos externamente (vs. glabros), frutos glabros o glabrescentes exteriormente en la madurez (vs. densamente ferrugíneo-vellosos o vellosos), muy esparcidamente puberulentos internamente (vs. vellosos), así como hojas con la lámina foliar mucho más pequeña $(4,2-9,5 \times 2-4,1$ cm vs. $(7-) 8,2-19(-20,1) \times 2,5-7,9 \mathrm{~cm}), \mathrm{y}$ preferencias ecológicas diferentes, ya que $C$. vulcanicus crece en bosques nubosos y ventosos ("elfin forest"), en elevaciones de 550 a $1200 \mathrm{~m}$, mientras que C. schultesii usualmente crece en bosques húmedos, bajo los $700 \mathrm{~m}$ de elevación. Connarus vulcanicus ha sido mal identificada en varios herbarios como Rourea schippii Standl., de la que en todo caso difiere por los caracteres genéricos antes mencionados.

El epíteto hace referencia a las localidades donde se ha recolectado esta especie, el cerro Cacao (un volcán extinto) y el Volcán Tenorio.

Paratipos: COSTA RICA. GUANACASTE: Parque Nacional Guanacaste, estación volcán Cacao, 9.II.1995, fl., L. Angulo et al. 48 (COL, INB, MO); 4.VI.1990, fr., U. Chavarría 39 (INB); 22.XI.1990, fl., C. Chávez 377 (CR, INB); 10.II.1995, fr., $B$. Gamboa 64 (COL, INB, MO); 8.II.1995, fr., $F$. Quesada 245 (COL, INB, MO); 4.VI.1990, fr., E. Rojas 35 (INB); idem, estación San Ramón, Dos Ríos, 21.IV.1993, fr., R. Espinoza 841 (INB, MO); idem, estación Pitilla, sobre la fila al cerro Orosilito, 25.V.1989, fr., R. Robles et al. 2808 (INB).

\section{Clave para las especies de Connarus en Costa Rica}

1. Flores sésiles o subsésiles; folíolos usualmente 3; inflorescencias y tallos jóvenes densamente ferrugíneo-tomentosos, el indumento obvio C. panamensis Griseb.

$1^{\prime}$. Flores pediceladas; folíolos 3-5; inflorescencias y tallos jóvenes puberulentos o glabrescentes, pero el indumento no ferrugíneo, diminuto.

2. Hojas y frutos usualmente con puntuaciones oscuras conspicuas; pétalos variadamente puberulentos en ambas caras C. lentiginosus Brandegee

2'. Hojas y frutos sin puntuaciones oscuras; pétalos glabros o esparcidamente puberulentos.

3. Folículos densamente ferrugíneo-tomentosos interiormente

C. costaricensis G. Schellenb

3’. Folículos glabros, glabrescentes, esparcidamente velutinos o esparcidamente puberulentos interiormente, el indumento no ferrugíneo.

4. Pétalos glabros por ambas caras; frutos glabros interna y externamente; vertiente caribe y Península de Osa, 0-500 m C. lambertii (DC.) Sagot

4'. Pétalos puberulentos en ambas caras; frutos esparcidamente puberulentos internamente; Cordillera de Guanacaste, 500-1200 m. C. vulcanicus J. F. Morales

\section{Agradecimilentos}

Se desea agradecer a los curadores de los herbarios COL, HUA, MO, NY por permitir el estudio de sus colecciones. Esta investigación fue posible además gracias al convenio de cooperación entre el Ministerio de Ambiente y Energía (MINAE) y el Instituto Nacional de Biodiversidad (INBio) con el fin de completar el Inventario Nacional de Biodiversidad en Costa Rica. 
ReFERENCIAS BibliográfiCAS.

Forero, E. 1983. Connaraceae. Flora Neotropica Monograph 36: 1-208. Organization for Flora Neotropica, The New York Botanical Garden, Bronx, New York, U. S. A.
\& F. González. 2001. Connaraceae. In: Stevens, W.; Ulloa, C.; Pool, A. \& Montiel, O. (eds.). Flora de Nicaragua. Monographs in Systematic Botany from the Missouri Botanical Garden 85(1): 651-653. 